\title{
\#stemfie: reconceptualising liveness in the era of social media
}

\section{Introduction}

I9 March 20I4 saw the breakthrough of a new kind of media text in The Netherlands: the stemfie. Being a portmanteau of the Dutch verb 'stemmen' (to vote) and 'selfie', the stemfie is a photo taken of oneself while (or just after) casting a vote, which is then shared through online social networks. As such stemfies are picked up by mainstream media and extensively spread through social media, they reveal how the global contemporary trend of the selfie is applied in media events like elections. In this article I will examine the stemfie as a contemporary example of the enactment of liveness within media practice.
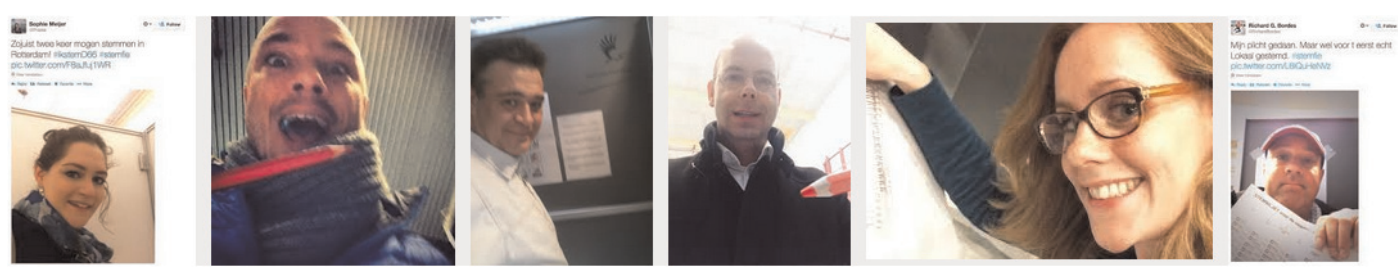

Ill. I. Stemfies posted 19 March 2014 (source: Google Images).

Ever since Daniel Dayan and Elihu Katz firmly incorporated the category of media events into media theory in the I990s, these events have been closely connected to the notion of liveness, as they describe the experience of being at and joining in an event as it takes place. ${ }^{\mathrm{I}}$ Others have indicated that the events we join through media are not restricted to the planned ceremonial events that Dayan and Katz defined as media events. Unfolding news events like 9/II and the crash of Malaysian airlines flight MHI7 in July 20I4, and entertainment-based reality TV events like BIG BROTHER and UTOPIA have also demonstrated the workings of liveness. ${ }^{2}$ Studying these events has shown that while immediacy is one of the key aspects of liveness, the concept should not be regarded as the equivalent of live; it is not simply the simultaneity of event, transmission and viewing. Liveness is here regarded as a historically defined construct that hinges on the potential connection, through media, to events that matter to us as they unfold. ${ }^{3}$

With social media taking such a prominent place within our current media landscape, the ways in which we participate in events through media nowadays differ greatly from twenty 
years ago, as the stemfie aptly demonstrates. Using multiple devices and platforms, users construct and navigate through stories, co-creating todays' media events. This development calls for a reassessment of existing theory on liveness. ${ }^{4}$

Inspired by the way in which José van Dijck applied actor-network theory (ANT) in her work on social media, I will take a techno-cultural approach to media, investigating the stemfie from three perspectives: media user, media content and media technology. ${ }^{5}$ Adhering to the conclusion that Karin van Es draws in her recent phD thesis on liveness, my main argument contends that because liveness is constructed within mediated practice, investigating it can provide insight into those practices. ${ }^{6}$ My main question is therefore twofold: what does the stemfie, by embodying immediacy and affinity, show us about how liveness is nowadays enacted in mediated practice?; and what does that tell us about users, content and technology within the current media landscape?

To address these questions I will first conceptualise liveness by examining how key authors have addressed the concept. Two steps will be made in this conceptualisation. Theory on media events will be discussed, identifying immediacy and affinity as the two core features of liveness. Secondly, I will argue that liveness is best regarded as a construction of user, content and technology. Subsequently, I will return to the stemfie to explore a contemporary enactment of liveness from the positions of media user, media content and media technology. This case study reflects the first steps of research into the subject; its ambition being mainly explorative and conceptual, aiming to discover changes in the ways that liveness is constructed within today's media landscape.

\section{Conceptualising liveness}

Liveness' two core features: immediacy and affinity

I have already characterized liveness as a historically defined construct that hinges on the potential connection, through media, to events that matter to us as they unfold. This paragraph focuses on the second part of this definition, arguing that liveness is determined by two main elements: immediacy and affinity.

Journalists, academics and industry professionals writing about the new medium of television in the I940s and I950s widely discussed its unique ability for allowing to 'see from a distance,' to bring world events into our personal space. The combination of home reception and immediate transmission is a very powerful one and inscribed immediacy and intimacy on the new medium. ${ }^{7}$ In this sense television extended the possibilities of radio, the first popular broadcasting medium that fundamentally changed the media landscape by enabling users to be directly connected to global events from the privacy of their homes. ${ }^{8}$ Within this power of radio and television to connect people directly to unfolding events that matter to them, we can discern two aspects that characterise liveness. First, radio and television had, and have, the capability to provide audiences with topical information the moment events happen and information is desired. I will refer to this as the 'immediacy' aspect of liveness. Strongly tied to this first aspect is the second: liveness means being connected through time and space, from our private spaces, with exactly those people and events that are important to us, making 
meaningful and intimate connections, and providing possibilities for involvement and participation. I will label this 'affinity'. These two aspects, immediacy and affinity, appear to be essential throughout academic conceptualisations of liveness.

Many media scholars have based their understanding of liveness more or less explicitly on the interplay of immediacy and affinity, choosing various terms for both features. Paddy Scannell and Karin van Es have explicitly done so quite recently. Scannell speaks of the 'immediate now-of-concern' and the 'meaningful now-of-concern'. ${ }^{9}$ Van Es refers to 'real-time connectivity' and 'sociality'. ${ }^{\text {Io }}$ Moreover, Nick Couldry, whose work has inspired my definition of liveness, characterises it as the guarantee of 'the potential connection to shared social realities as they are happening'. ${ }^{\text {II }}$ Since my focus is on liveness within media events, I will trace the elements of immediacy and affinity within academic work in three main categories of media events: the ceremonial event, breaking news, and reality television.

In their seminal work on media events, Dayan and Katz take an anthropological approach, explaining how media events work to articulate belongingness - affinity - and connect large audiences in a longing for a shared centre. They concentrate on pre-planned live broadcasts of ceremonial events that offer the audience a participatory role in witnessing. ${ }^{22}$ Watching a live event is being a witness to a unique moment in time while the event is taking place and 'witnesses are forever irreplaceable in their privileged relation to it'. ${ }^{33}$ This is exactly what we, as 'audience', as 'fans', as 'citizens' long for, we want to be part of history as it is unfolding and this is what being present in time brings us. ${ }^{14}$ This example relates both the aspect of immediacy witnessing something as it happens - and of affinity - the connection to events that matter in our history. The perception of immediacy is strengthened by the fact that even though these events are planned, they are interruptions of our daily routines and broadcasting's schedules. Although heavily pre-produced, the live nature of these broadcasts enhances the possibility of something unplanned or unexpected happening. ${ }^{15}$

Where Dayan and Katz focus on ceremonies, for instance excluding John F. Kennedy's funeral, others have chosen to focus on the exact opposite: breaking news. Addressing the catastrophic media event - wars, assassinations, attacks, accidents, riots - Mimi White argues that events develop 'through ongoing co-articulations of liveness and historicity'. ${ }^{\mathrm{I}}$ Reporting in media events, she says, tends to emphasise our privilege of being there while history unfolds; in a highly self-conscious way media texts articulate past, present and future in their construction of liveness. In White's claims that liveness is present and past at the same time we find the aspects of immediacy (present) and affinity (a shared past). Here we get closer to the essence of liveness: it is not the equivalent of the live event itself, but rather a mediated construction in which the live event (immediacy) is combined with the reflection on or historical narrativisation of it (affinity). During so-called 'disaster marathons', a recent Dutch example being the live broadcasts after the MHI7 airplane crash in July 20I4, we often follow a continual stream of reports and images that do not necessarily give us any new information speculations of a reporter nearby, video material of smoke in the area, live footage of an airportbut give us the idea of being there. ${ }^{17}$ Liveness is constructed through the combination of images of the present and the narrative connecting them to history. Writing about the marathon of disaster that was the 2008 Mumbai attacks, Sangeet Kumar also discerns the 
aspects of immediacy and affinity, claiming that being present in time and the promise of a communal experience make up for the gap in space between audience and event, thus establishing liveness. ${ }^{\mathrm{I}}{ }^{8}$

With the creation of the reality television genre, the I990s saw the birth of a completely new type of media event. These media events - like the global success of the BIG BROTHER format did not connect viewers to grand historical, disturbing world events; rather they provided live footage of the mundane, everyday activities and social interactions of 'ordinary' people: ${ }^{\text {:9 }}$ People that viewers could relate to combined with the tension of directly watching non-fictional characters within a plot-less soap opera setting - again connecting immediacy and affinity - make many viewers consume seemingly meaningless images. And audiences did not only watch BIG BROTHER; these first multi-platform media events compelled viewers to participate by following the show every minute of the day by actively switching from the TV to the Internet, exchanging information with other viewers, and by voting. Committed commentators, viewers and voters were writing and influencing the storyline and plot, co-constructing the format and making it cohere. ${ }^{20}$ This element of active audience participation across platforms, Espen Ytreberg argues, extends liveness by involving audiences as participants and thus providing them with a stronger sense of immediacy. It is liveness that makes these formats work, which is crucial for creating the temporal unification they need. ${ }^{2 \mathrm{I}}$

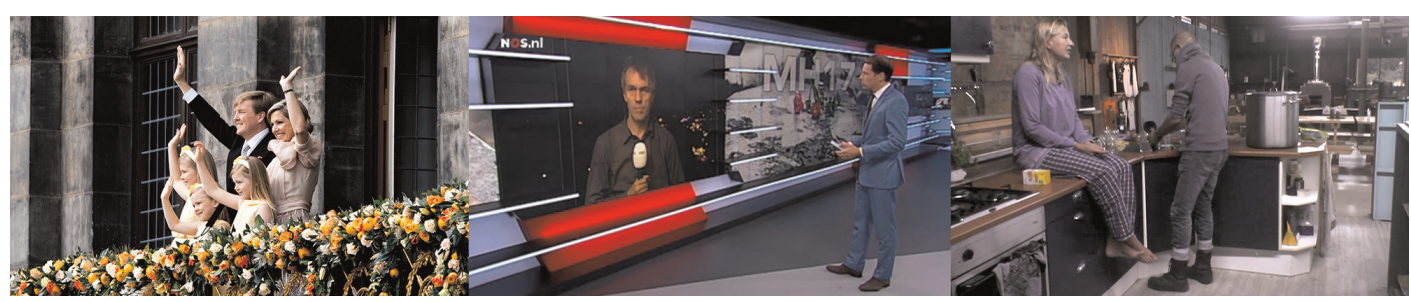

Ill. 2. Examples of the three types of media events, from left to right: balcony scene on the day of the inauguration of King WillemAlexander (source: ANP); news marathon after the MH17 airplane crash (source: NOS); live stream of reality show UTOPIA (source: Talpa).

This discussion of the three main types of media events - the ceremonial, breaking news and multi-platform reality events - makes clear that in all of them immediacy and affinity can be discerned as the two core features of liveness. What also becomes apparent when looking at multi-platform reality events like BIG BROTHER is that liveness appears to have become a crossmedia construction. ${ }^{22}$ The latter point will be taken up in the next paragraph.

Liveness as construction of user, content and technology

After characterising liveness as interplay of immediacy and affinity, it is time to turn to the first part of my definition - namely, liveness as a historically defined construct. I will here argue that liveness is best regarded as a configuration of media user, media content and media technology. By doing this I am taking a techno-cultural position, influenced by actor-networktheory (ANT), aiming to examine connections between human agents, technologies and objects. ${ }^{23}$ This configuration mirrors the techno-cultural part of Van Dijck's analytic model 
for researching social media. ${ }^{24}$ This paragraph briefly addresses how liveness has been conceptualised until now, after which it will propose that within the current media landscape, liveness is best approached as a construction of user, content and technology.

For scholars and users alike, television is the 'live medium' par excellence. Combining the moving image with sound, and the possible simultaneity of event, transmission and viewing, liveness seems inscribed in the medium's qualities. Liveness was, and often still is, hailed as an ontological or technological feature of television; in the I940s and I950s it was mainly used as a professional term to distinguish television from cinema or theatre. ${ }^{25}$ Jane Feuer was one of the first to conceptualise liveness not as a technological attribute, but as an ideological quality of television. She pointed out that, even though by the ig 80 s most television programmes were a collage of live and recorded sequences and most broadcasting was not strictly live, the aesthetic of most programmes was based on the idea of liveness. ${ }^{26}$ Robert Vianello adds to that by demonstrating how the perpetual possibility of connecting to actual events permeates all broadcasting and anchors television in 'the real'. This is what Vianello claims to be the ideological power of television. ${ }^{27}$

By the beginning of the $2 \mathrm{I}^{\text {st }}$ century, the popularity of 'new media' like the Internet and the mobile phone - and the way these are integrated in multi-platform reality formats like BIG BROTHER - points out that liveness is not necessarily connected to the medium of television or the phenomenon of broadcasting exclusively. In 2004, Couldry distinguished the influence of these new media, introducing the concepts of 'online liveness' and 'group liveness' as new and non-televisual forms of liveness. By looking at it as a category in Durkheim's sense, Couldry claims that liveness is a sociological construct rather than a technological attribute of or an ideology connected to one dedicated medium. ${ }^{28}$ Philip Auslander, taking a more phenomenological perspective, follows 'Gadamer's argument that we engage with works of art as contemporaneous' and places liveness in the relationship between user and medium, claiming that the user puts as much into the construction as the medium does. ${ }^{29}$ Scannell also takes the phenomenological approach in his latest book Television and the meaning of 'live' (2014). Although his focus is on television, his conceptualisation of liveness does not rest on medium specificity. ${ }^{30}$

Summing up, within media studies liveness has been positioned either as technological quality, as ideology or as affect. In the past decade academics have broadened the concept to encompass more media than simply television. Building on this, I believe that approaching liveness as a construction of user, content and technology will enable scholars to reflect more critically on prevailing media practices..$^{3 \mathrm{I}}$ The current media landscape displays a diversity of converged media and social platforms, widely used on mobile devices, which trace a new silhouette of an 'ecosystem of connective media'32 in which liveness might be constructed in particular new ways. Rather than introducing new forms of liveness to fit these developments e.g. Couldry's online and group liveness or Auslander's digital liveness - the view of liveness as construction, as being constructed within media practices, enables us to retain the concept. Moreover, as the elements of user, content and technology continuously change, as does their interplay, this construct of liveness provides us with a critical perspective to investigate the ways in which these elements interact within current media practices. Being dissociated from any 
specific type of media, this conceptualisation of liveness provides a durable model to consider changes in the media landscape, and is applicable to every new medium or type of media text.

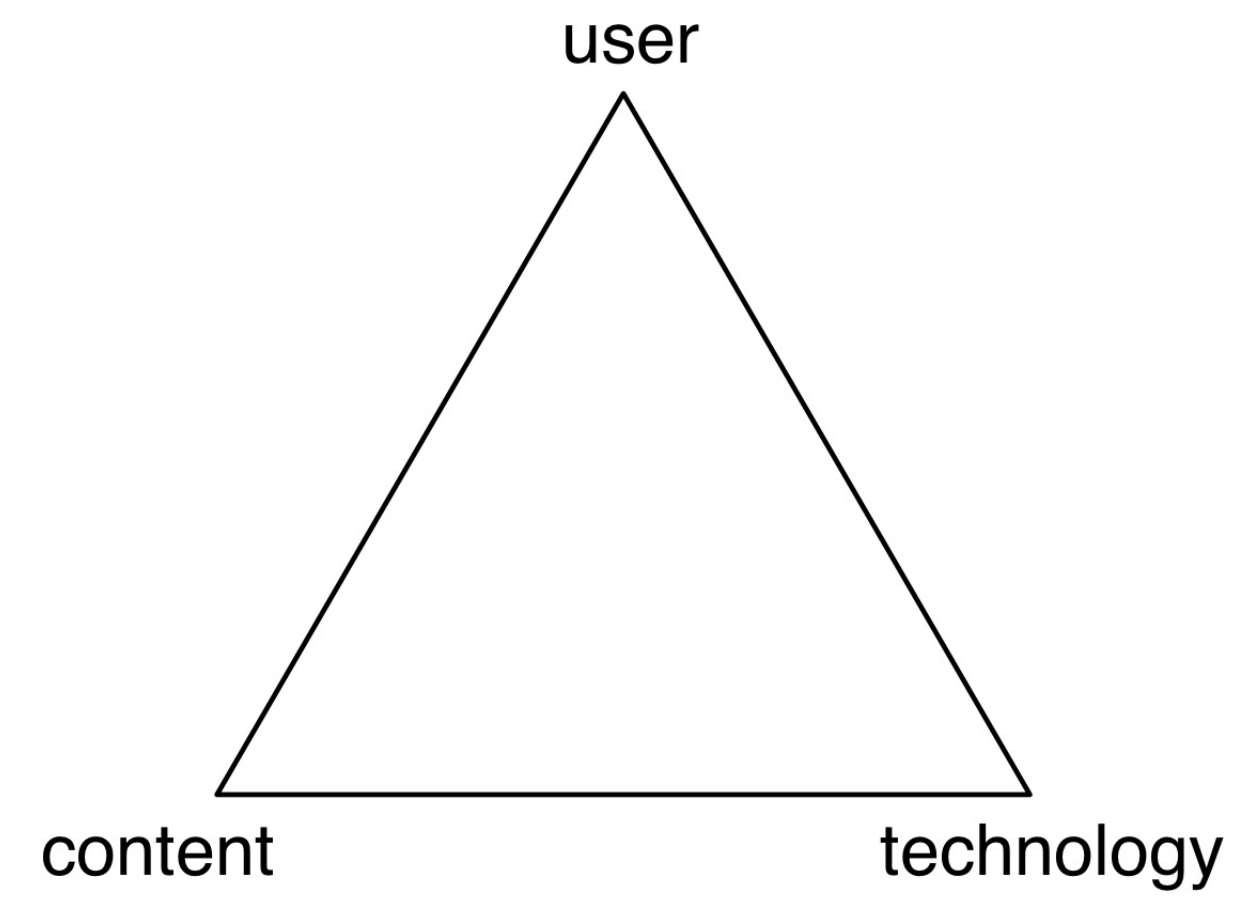

Ill. 3. Liveness as construction of media user, media content, and media technology.

The subsequent explorative analysis will apply my conceptualisation of liveness to the present-day media practice of the stemfie while relating this example to recent media theory. The stemfie is an interesting current example of the enactment of liveness within mediated practice because it exemplifies how we use media to connect to events that are important to us as they unfold, thus combining immediacy and affinity; and because it provides insight into the ways in which user, content and technology interact within current media practices. Two questions will guide the exploration:

I. How does the stemfie connect us to an event that is important to us as it unfolds, enacting the liveness aspects of immediacy and affinity?

2. Which user, content and technological practices are at play?

I will now briefly introduce the stemfie after which one specific stemfie will serve as a case study which will be examined from the three constructing perspectives of (media) user, (media) content and (media) technology.

\section{\#stemfie}

Taking a picture of oneself is not something that we would immediately associate with liveness. However, the way in which these pictures are commonly produced, distributed and received nowadays is a perfect example of how liveness is constructed within the current media 
landscape. A selfie can be taken anytime, anywhere and can be shared instantaneously; it can reflect a very personal experience. Increasingly we see selfies connected to public events, as elements of media events. An example of this was the 'stemfie' during the Dutch municipal council elections on ig March 20I4.

Elections are a specific kind of media event during which media enable us to connect to a shared invisible reality: the event is made up of many moments during the day, happening at different places simultaneously. 'On the ground' you cannot take in the full event; only through media do we have privileged access to it. Only via media can we be in multiple voting booths, in several town halls and in the locations where the forecasts and results are presented. Only through media can we see the elections from the perspectives of the voter and the non-voter, of the local and the national politician and of a range of experts. In addition, it is the sense of immediacy and affinity that invite the audience to make all these temporalities and locales cohere. ${ }^{33}$ The March election was a typical example of this: all day long broadcast and social media were filled with content related to the local elections, climaxing in the evening when everyone awaited (the prognoses of) the results. In this particular case, the stemfie took over on social media, and was consequently discussed on radio, television and in the newspapers. ${ }^{34}$

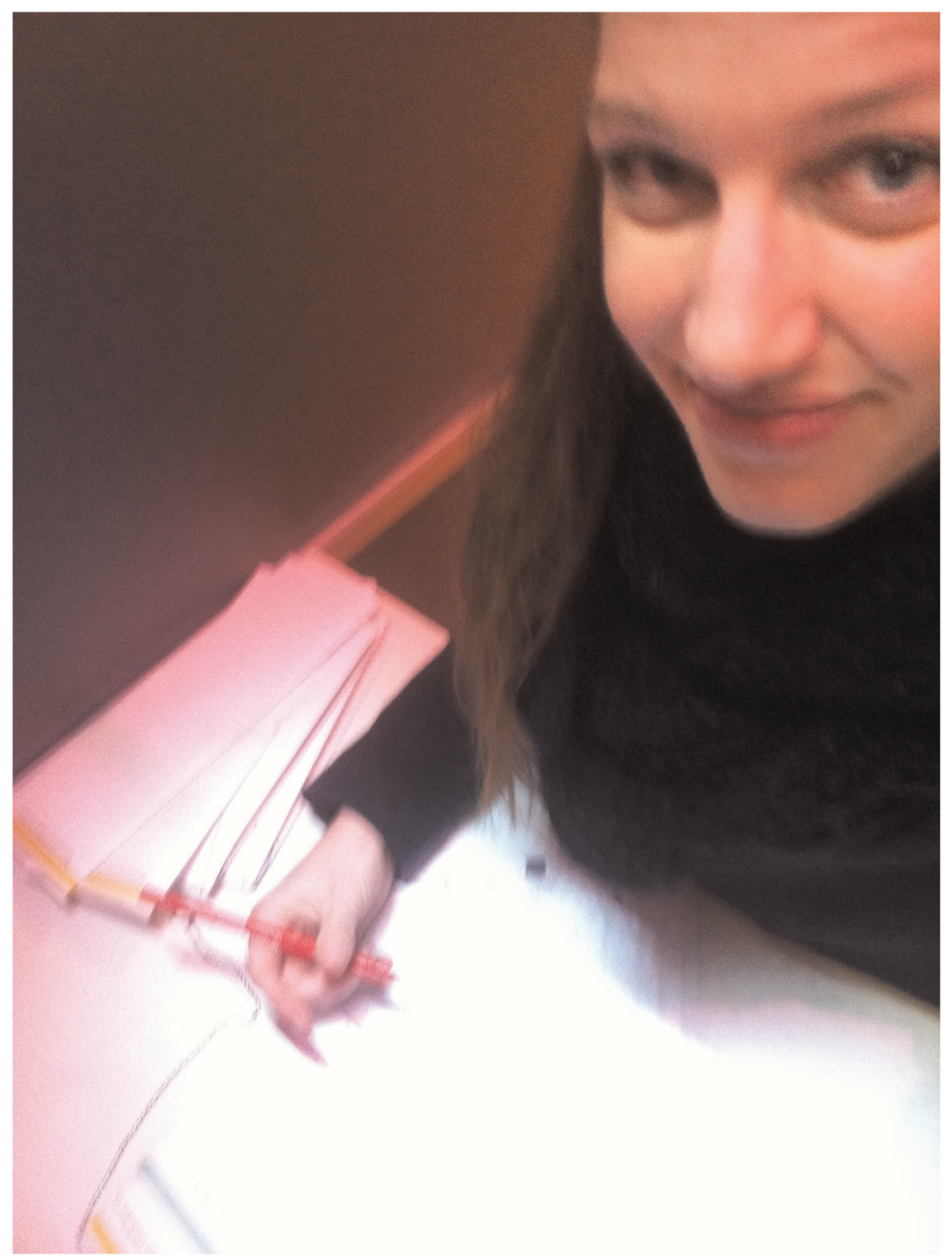

Ill. 4. Stemfie by Sue (source: personal archive). 
Media user: new position, new responsibilities?

In the stemfie illustration 4 shows, you can see my friend, Sue. On I9 March she posted this picture as a status update on Facebook with the caption: 'Selfie with Maurice and Martijn for Asher! - at De Balie Amsterdam' [all names are pseudonyms given by author]. Maurice and Martijn are her fiancé and a friend who were out of town and had authorised her to cast their votes. Asher, also a friend of Sue's, is the local politician she voted for. By posting this picture and caption, Sue shared casting her vote with her Facebook friends, tagging all three people involved and therefore involving anyone who Facebook friends with them too. How can we understand this user practice in the sense of liveness? What does this stemfie tell us about the way Sue connects to an event that matters to her as it unfolds?

As we have seen in the discussion of multi-platform reality formats, the possibility of participating in a media event as co-creator truly changes the meaning of liveness for the user. This active form of participation exceeds the experience of participating vicariously as part of a broadcast audience. ${ }^{35}$ The possibility to influence and be noticed within an event, Ytreberg claims, enhances the sense of liveness. ${ }^{36}$ Of course, aside from the media event, in elections you influence the outcome by voting. This influence is minor, however, and far from noticeable in the larger media event. The stemfie provides a possibility for the voting citizen to write himself into the media event of the elections, to influence them and to be noticed. And with that the stemfie amplifies the experience of being connected to the shared reality of elections as the event takes place.

The way the stemfie is employed to actively co-create the media event underlines the need of the user to be very conscious of and experienced with the possibilities and conventions of media. Since Sue has seen many of these events before, she knows the standard scripts of election day, and the different locations and perspectives of the event where she is able to position herself. This does not mean that she knows how the media event, and her stemfie, will turn out. As Kumar has pointed out, media events are open-ended and the definite plot and meaning of the event can only be constructed afterwards. ${ }^{37}$ Only when the full event has passed, and maybe even only when main 'scenes' have been rerun, analysed and commented upon by users, journalists and experts, can we see the event's full picture and meaning. Experienced media users know this. And this augments the user's sense of liveness in the act of posting a stemfie. The open-endedness of the unfolding media event and the knowledge of the various locales and temporalities therein invite the user to participate in the moment. Sue knows that she is just a small part of the unfolding event; nonetheless, she is part of it while it happens.

As discussed before, the audience has always been involved in media events as a witness, and this is not a plain and simple position. Being involved or related to an event as a witness comes with responsibilities. One cannot shrug their shoulders, turn around and pretend it never happened. One has to at least acknowledge the event took place, and ethically it can be argued that this compels the responsibility to act. This is also why many of us find it important to follow the news: since we have a responsibility to act in the world and can only act in the present, it is important for us to know what is happening now. ${ }^{38}$ Taking this argument from 
the broadcast system to the social media landscape, the user might be described, following David Berry, as a riparian user: since the recent restructuring of the web and web-based social media into streams, the user, with his responsibility to act, 'is expected to desire the real-time stream, both to be in it, to follow it, and to participate in it'. ${ }^{39}$ This is how Sue's election day stemfie can be seen: following the media event stream and actively participating by adding to it.

Not only does this active form of participation boost presence as Ytreberg has said, it also implies new responsibilities for the user. With the growing importance of user-generated content, it is more and more the case that an event does not exist as such, but is being cocreated as it is being reported through media. As Kumar explains:

'Far from unfolding at a distance and separated from those witnessing it, media events in a networked world are on a feedback-loop of relentless course correction in response to what is being reported. (...) As each participant is also a veritable node in the media network, no event can unfold in isolation from its witnessing. (...) The cause and the effect become intertwined in an inseparable swirl here'. ${ }^{40}$

A similar point can be made for media events in the broadcast era-they always influence the event itself. However, this is amplified in the current media landscape in which interaction, user participation and user-generated content are omnipresent. Furthermore, this reciprocity in media events and the performing position of the user therein causes a shift in accountability. In media events in which both broadcast and user-generated social media texts influence the course of events, what is the responsibility of media outlets and of users?

\section{Media content is used to position oneself in history}

From a content perspective the possibility of co-creating media events is also a point worth regarding. As Ingrid Volkmer and Florian Deffner point out, in the current media landscape 'a media event is not only "mediated" in many different cultural forms but is discursively remediated through individual sites, blogs, and comments on digital platforms'.$^{4 \mathrm{I}}$ Nowadays, the content of a media event is spread over diverse platforms and all those who - as riparian users see, hear, add and manage circulating media texts, renegotiate and reposition the event. Because of this, Volkmer and Deffner introduce the term 'eventspheres' to more fittingly describe the workings of media events in the era of social media.

One of the fundamental changes that this shift from scripted media events to co-created eventspheres has brought about is that content seems closer to the user. While broadcast media have always had to work hard to overcome the distance between the event's story and the audience, networked communication structures discourse to create proximity. As John Fiske argues, in the broadcast era we already appropriated content by adding our own meaning to it and by connecting it to our social relations and identities. ${ }^{42}$ Getting news out of the stream of social networks and having your own network overlap with the eventsphere makes the news come from a 'friend,' or at least someone with whom you have actively made a connection; such 
'friend-delivered' content will more likely reflect affinity. ${ }^{43}$ Sue's stemfie in my Facebook timeline feels more relevant and closer than a photograph of a random voting citizen in a newspaper.

By co-creating the eventsphere through streams that are close to us, the stemfie's author positions herself within shared narratives or storylines as they develop, incorporating them into everyday life. In Sue's case, three narratives emerge in which she claims her role. Although I believe that there is a sense of liveness at work in all three, the third more clearly shows immediacy and affinity in the media event context of the elections. I will thus only briefly refer to the first two narratives and then focus on the third. The first narrative is the interpersonal story within Sue's inner social circle, telling Asher, Maurice and Martijn of her vote, which can be regarded as a practice of circulating media texts as a means to strengthen social bonds among friends. ${ }^{44}$ The second story told is the one of Sue's identity. By sharing the post with her larger social circle of Facebook friends and, by tagging them, those of the three involved persons, Sue manifests herself as the friend of a candidate, as trusted friend of Maurice and Martijn and as a voting citizen, as well as stating her political preference. ${ }^{45}$ Third, Sue's stemfie reaches out of her social circle and places her within a nationwide narrative about the local elections. For weeks and especially days before the elections, broadcast media were anticipating a low voter turnout. Many media predicted that the percentage of people voting would be 'historically low'. Several well-known Dutch figures did their best to galvanise people to vote. For instance, the mayor of Amsterdam invited twenty celebrities - football players, actors, writers, rappers, etc. - to his home for breakfast on election day. ${ }^{46}$ This group of influential citizens of Amsterdam with a large presence on Facebook and Twitter then called on their online followers to go and vote. This is also how the stemfie functioned that day. By sharing that you vote, you call on your social connections to do the same, in other words you are using social media to 'build community and awareness around the subjects [you] care about'. ${ }^{47}$

This third narrative can be regarded as joining in a historical narrative. As we have derived from White's argument, liveness is present and past at the same time, and the sense of immediacy and affinity rests upon the historicity of the media event. The historical narrative makes an event important to connect to as it happens, becoming part of history as it unfolds. ${ }^{4}$ The image of the stemfie itself would be meaningless without the connection to the historical narrative that is articulated through multiple platforms. This connection creates the sense of immediacy and affinity that is crucial for binding all the circulating media texts in the eventsphere. The stemfie, being user-generated content, occupies a unique position herein. As addressed above, Sue is not only witness to an event through media, she is also physically present at one of the event's locales and being there in time and place positions her in a different way than being there as, for instance, a television viewer. Consider John Peters' distinction: between being able to say 'I was there' and 'I saw it on television'. 49

By posting her stemfie, Sue skilfully positions herself in the historical timeline of the media eventsphere of the Dutch local elections of 20I4. Her photo shows that she is there while history is unfolding, perfectly combining immediacy and affinity. This sense of liveness connects her stemfie to all other media texts in the elections' eventsphere, while the way that she shares this content through networked communication establishes proximity in ways that 
broadcast media never could. As we will turn to the factor of technology, this issue of proximity will be addressed further.

\section{Media technologies are ubiquitous: intimate, personal and always connected}

Approaching Sue's stemfie from a technological perspective, I will describe how immediacy and affinity are established through three technological features of this media text: the real-time stream, wireless connectivity and the personal snapshot.

The organisation of the web and of social media in real-time streams profoundly influences the media landscape in which Sue's stemfie is situated, by combining the proximity of the stream with immediacy. Increasingly, the web appears to revolve around flows of data being distributed, produced and aggregated by users and their devices..$^{\circ}$ Real-time streams, like our Facebook timeline, provide us with the belief that we are following and participating in 'what is happening right now'. We can see the new dress a friend bought, extend our search for a house, see the first pictures of our cousin's baby, get the news about an airplane crash and see our friend voted. As these examples show, however, these real-time messages are all stills in time. ${ }^{5 \mathrm{I}}$ Recently, more and more authors have started to regard 'real-time' critically and it is becoming clear that the network society creates and is depended on various coexisting temporalities. ${ }^{2}$ For me, these critical views of real-time resonate the work of Feuer and Vianello: the idea of true immediacy is naive, but these real-time streams do create a sense of now-ness, of tapping into events as they are unfolding and with that accommodate the need for immediacy so central to liveness.

Not only the network of real-time streams but also how we tap into these streams through such mobile media as the smartphone embody this ideal of immediacy. As Manuel Castells notes, 'the key feature of wireless communication is not mobility but perpetual connectivity'. ${ }^{53}$ This is what having our smartphone on hand means to us: we are always connected to our friends and also to the larger world outside of our social circle. We know that, in the event of something important happening we will receive a call from our child's day care, a push message from a news service or a status update from a friend. 'Having a wireless communication device like a mobile telephone at one's disposal implies having access to ever-present, real-time communication channels, and thus to the means to engage in dialogue or to disseminate information whenever and wherever one wants', says Imar de Vries. ${ }^{54}$ Many authors have pointed out that these discourses of immediacy around media reflect UTOPIAn myths of ultimate communication and it is this ideal that I recognise in what Couldry describes as the potential of liveness. ${ }^{55}$

The smartphone not only provides a sense of perpetual connectivity; being the single most nearby piece of technology in everyday life for so many users it is also a very intimate form of technology, establishing affinity. ${ }^{56}$ This intimacy is created by two factors: the smartphone is up close - omnipresent in our everyday lives and personal space - and personal - a highly customisable device carrying very personal content. As Jane Vincent notes: 'The mobile phone is constantly at hand, often constantly in the hand, and filled with the personal biography of its user'. ${ }^{57}$ The mobile telephone is everywhere and it has blended into our daily lives and social activities. ${ }^{5}$ It is with you wherever you are. We keep it on our desk at work, we bring it to the 
toilet, it lies next to our beds while we sleep. The smartphone is ubiquitous; it accompanies us within our personal space and intimate locales and has become an indispensable part of ourselves. The second factor that makes the smartphone such an intimate technology is the highly personalised character of the device. Being a multi-functional device with a large internal memory and various ways of connecting, the smartphone caters to the user's personal needs and preferences. We personalise it by choosing ringtones, restricting access with a personal code, choosing the applications that are on it; we add all our personal contacts and photos, we manage our bank account with it as well as call our mother. It is our most prominent tool for monitoring streams and aggregating data flows. ${ }^{59}$ The smartphone has, as Vincent states, 'become a personal compendium for the life of the user and one that reflects intimate aspects of their self, not shared with any other person or device apart from their own mobile phone'. ${ }^{6}$

Finally, I will address one final technological feature of Sue's stemfie, regarding it as a personal snapshot, handheld, from a personal perspective. The personal snapshot has quite an intimate character. For decades these photos were made as personal mementos meant to be kept in a personal archive - the photo album or shoebox - or, most publicly, on the wall in people's homes. The personal photo belonged to the private domain and was shared only with inner social circles. ${ }^{61}$ As the stemfie and the underlying trend of photo sharing on social media platforms demonstrate, in the current media landscape the personal photograph is regularly used as a communication tool, turning the private into the public. ${ }^{62}$ Still, the intimate personal feel of the snapshot remains. This combined with the camera phone's pervasiveness in capturing the special and mundane moments of everyday life and the way we see it as an extension of ourselves, makes these images strongly personal and associated with an individual viewpoint. $^{63}$

\section{Conclusion}

This essay has shown the stemfie to be an interesting current example of the enactment of liveness within mediated practice. The photo taken of oneself while (or just after) voting and consequently shared with others via online social networks connects us to an event that is important to us as it unfolds. Furthermore, it provides insight into the ways in which media user, media content and media technology interact within current media practices.

Examining the stemfie Sue posted has brought insight into some of the specific ways in which media practices have changed in the social media era. First, the position of the user has fundamentally changed from witness to co-creator of the media event. The sense of immediacy and affinity that establish liveness are crucial in creating temporal unification in the media event. Because of this aura of liveness, and the knowledge the user has of media events, she can skilfully position herself in one of its locales. This active participation boosts liveness by making the user feel noticed and influential. Furthermore, new dynamics in the media landscape, in which broadcast and social media have a reciprocal relationship through re-using each others' texts cause a shift in accountability. The growing influence of the user as co-creator of media events, and the impact that this has on the course of events, raises the question of the users' responsibilities. When addressing the stemfie from a content perspective, I have adopted the term media eventsphere from Volkmer and Deffner since it so accurately describes how media 
events are currently composed by various flows and pieces of content. The stemfie exemplifies this and adds the personal feel of content that comes to us through our social networks. Moreover, it shows us how user-generated content within an eventsphere is used to position oneself in history. The stemfie embodies the desire to be there 'while it happens' and consequently become part of a shared narrative, establishing the historicity that strengthens both immediacy and affinity. Furthermore, examining the technological features of the stemfie reveals how present-day ubiquitous technologies bolster our sense of immediacy and affinity. Sue's stemfie incorporates both the embodiment of the ideal of immediate connection in the real-time stream and wireless connectivity, and the articulation of affinity by the personal and intimate character of the smartphone and the personal snapshot.

For this paper I have chosen to focus on a specific type of social media text, the stemfie, to discern the unique way in which liveness is constructed via and around it. What has not been taken into account here is the role of broadcast media in current eventspheres. This limiting of scope was done solely for pragmatic reasons; I am convinced that, although specific roles and characteristics have changed, both broadcast and social media are essential in our current experience of media events. Especially during larger national or global events, broadcast and social media texts commingle to co-create an event as they did in the local elections on I9 March 20I4. As this point has not been fully addressed here, it remains open for future research. In an analysis of the interactions and confluence of broadcast and social media, the aforementioned point of media outlets' and users' responsibilities would be a good one to explore.

In conclusion, the core features of liveness - immediacy and affinity - have remained essential within the social media era; however, a changed media landscape does show new ways of articulating them. Liveness should not be viewed as a quality of a specific medium, but rather as a construction around media or a cross-media construction. Taking a techno-cultural position, I believe that approaching liveness as a construction of user, content and technology enables scholars to more critically reflect on prevailing media practices. This particular approach provides a model for further research, for instance, for empirical fieldwork on liveness that would fill a void in the field. As it is made up of dynamic elements, this construct of liveness invites critical reflection on, and offers insights into, the ways in which user, content and technology interact within current media practices. Being applicable to any (new) medium or media text, it provides scholars and media professionals alike with a durable model to reflect on changes in the media landscape.

\section{Notes}

I. D. Dayan \& E. Katz, Media events: the live broadcasting of history, Harvard University Press, Cambridge/ London I992.

2. Cf. M. White, 'The attractions of television: reconsidering liveness', in: N. Couldry \& A. McCarthy (eds), Mediaspace: place, scale, and culture in a media age, Routledge, London/New York 2004, p. 75-9I; S. Kumar, 'The fatal snare of proximity: live television, new media and the witnessing of Mumbai attacks', in: South Asian history and culture, 3, vol. 4, 20I2, p. 5320548; P. Lunt, 'Liveness in reality television and factual broadcasting', in The communication review, 7, vol. 4, 2004, p. 329-335; N. Couldry, 'Playing for celebrity: Big Brother as ritual event', in: Television a new media, vol. 3, 2002, p. 283-293. 
3. I have based this definition of liveness on the following three sources: R. Vianello, "The power politics of "live" television', in: Journal of film and video, 37, vol. 3, I985, p. 26-40; N. Couldry, 'Liveness, "reality," and the mediated habitus from television to the mobile phone', in: The communication review, 7, vol. 4, 2004, p. 353-36r; P. Auslander, 'Digital liveness: a historico-philosophical perspective', in: PAJ: A journal of performance and art, 34, vol. 3, 2OI2, p. 3-II.

4. An appeal also made in Couldry, 'Liveness, "Reality," and the Mediated Habitus'; and K. van Es, 'The paradox of liveness: from the broadcast media era to the social media era', phD thesis, Universiteit Utrecht, Utrecht 2014.

5. J. van Dijck, The culture of connectivity: a critical history of social media, Oxford university press, Oxford 2013.

6. Van Es, The paradox of liveness.

7. R. Berenstein, 'Acting live: TV performance, intimacy, and immediacy (I945-I955)', in: J. Friedman (ed.), Reality squared: televisual discourse on the real, Rutgers university press, New Brunswick 2002, p. 25-49.

8. M.J. Matelski, 'Resilient radio', in: E.C. Pease \& E.E. Dennis (eds), Radio: the forgotten medium, Transaction publishers, New Brunswick/London, I995, p. 5-I4; D. Bartlett, 'News radio: more than masters of disaster', in: Pease and Dennis, Radio: the forgotten medium, p. 3I-4I.

9. P. Scannell, Television and the meaning of 'live': an enquiry into the human situation, Polity press, Cambridge, 20I3.

Io. Van Es, The paradox of liveness.

II. Couldry, 'Liveness, "reality," and the mediated habitus'

I2. E. Katz \& D. Dayan, 'Media events: on the experience of not being there', in: Religion, I5, vol. 3, I985, p. 305-3I4; Dayan \& Katz, Media events; J. Corner, 'Television's “event worlds” and the immediacies of seeing: notes from the documentary archive', in: The communication review, 7, vol. 4, 2004, p. 337-343.

I3. J.D. Peters, 'Witnessing', in: Media, culture a society, 23, vol. 6, 200I, p. 707-723, p. 7I8.

I4. Peters, 'Witnessing'

I5. Dayan \& Katz, Media events.

I6. White, 'The attractions of television', p. 78.

I7. About disaster marathons see E. Katz \& T. Liebes, “No more peace!”: how disaster, terror and war have upstaged media events', in: International journal of communication, vol. I, 2007, p. I57-I66.

I8. Kumar, 'The fatal snare of proximity'.

I9. Lunt, 'Liveness in reality television and factual broadcasting'.

20. R. Rustema, 'Big Brother als "pure televisie”', in: M. Reesink \& I. Costera Meijer, Reality soap! Big Brother en de opkomst van het multimediaconcept, Boom, Amsterdam, 2000, also on: www.icce.rug.nl/ soundscapes/vOLUMEO3/ Big_Brother.shtml; J. Roscoe, 'Multi-platform event television: reconceptualizing our relationship with television', The communication review, 7, vol. 4, 2004, p. 363-369; E. Ytreberg, 'Extended liveness and eventfulness in multiplatform reality formats', in: New media Q society, II, vol. 4, January 2009, p. 467-485.

2I. Ytreberg, 'Extended liveness'.

22. Couldry, 'Playing for celebrity'.

23. Latour, Reassembling the social; Couldry, 'Actor network theory and media'.

24. Van Dijck, The culture of connectivity.

25. Cf. J. Bourdon, 'Live television is still alive: on television as an unfulfilled promise', in: Media, culture Q society, 22, vol. 5, 2000, p. 53I-556; H. Zettl, 'The rare case of television aesthetics', in: Journal of the University film association, 30, vol. 2, I978, p. 3-8; Berenstein, 'Acting live'.

26. J. Feuer, 'The concept of live television: ontology as ideology', in: E.A. Kaplan (ed.), Regarding television: critical approaches - an anthology, American film institute, Los Angeles I983.

27. Vianello, 'The power politics of "live” television'.

28. Couldry, 'Playing for celebrity'; N. Couldry, Media rituals: a critical approach, Routledge, London/New York 2003; Couldry, 'Liveness, "reality," and the mediated habitus'.

29. Auslander, 'Digital liveness', p. 8.

30. P. Scannell, Television and the meaning of 'live'.

3I. Van Es in The paradox of liveness, also argues for regarding liveness as construction to invite critical reflection. However, in her approach, liveness is a construct of metatext, space of participation and user responses.

32. Van Dijck, The culture of connectivity, p. 2I.

33. S. Marriott, 'Election night', in: Media, Culture Q Society, 22, vol. 2, 2000, p. I3I-I48; Dayan \& Katz, Media events; Ytreberg, 'Extended liveness'. 
34. Following the elections of I9 March there has been much discussion and a lawsuit about the stemfie in The Netherlands, as some regard it to be an infringement on the privacy of voting. Worldwide we see the stemfie trending in France in March and being prohibited in Belgium, Great Britain and South Africa.

35. Ytreberg, 'Extended liveness'; S. Livingstone, 'New media, new audiences?', in: New media \& society, I, vol. I, I999, also on: eprints.lse.ac.uk/39I/I/N-media\&societyI(I).pdf.

36. Ytreberg, 'Extended liveness'.

37. Kumar, 'The fatal snare of proximity'.

38. Peters, 'Witnessing'.

39. D. Berry, The philosophy of software: code and mediation in the digital age, Palgrave Macmillan, Basingstoke 2OII, p. I43.

40. Kumar, 'The fatal snare of proximity'.

4I. I. Volkmer and F. Deffner, 'Eventspheres as discursive forms: (re-)negotiating the "mediated center" in new network cultures', in: N. Couldry, A, Hepp and F. Krotz (eds), Media events in a global age, Routledge, London 20IO, p. 224 .

42. J. Fiske, Reading the popular, Unwin Hyman, Boston 1989.

43. H. Jenkins, J. Green \& S. Ford, Spreadable media: creating value and meaning in a networked culture, New York university press, New York 2013.

44. Cf. Jenkins et al., Spreadable media.

45. Cf. Jenkins et al., Spreadable media; D. Boyd, 'Taken out of context: American teen sociality in networked publics', phD thesis, University of California, Berkeley, 2008.

46. 'Van der Laan bakt eitjes voor BN'ers', op: Telegraaf.nl, I9 March 20I4, retrieved from http://www.telegraaf.nl/ binnenland/verkiezingen20I4/22403279/_Ontbijt_BN_ers_bij_burgemeester_.html, (viewed April 20I4).

47. Jenkins et al., Spreadable media, p. 304.

48. White, 'The attractions of television', p. 78.

49. Peters, 'Witnessing', p. 7I8.

50. Berry, The philosophy of software.

5I. D. Rushkoff, Present shock: when everything happens now, Penguin group, New York 2013.

52. Cf. Rushkoff, Present shock; R. Hassan, 'Network time and the new knowledge epoch', in: Time \& society, I2, vol. 2-3, 2003, p. 225-24I; R. Hassan \& R.E. Purser (eds), 24/7:time and temporality in the network society, Stanford business books, Stanford 2007; E. Weltevrede, A. Helmond \& C. Gerlitz, 'The politics of real-time: a device perspective on social media platforms and search engines', in: Theory, culture Q society, 3I, 6, 20I4, p. I25-I50.

53. M. Castells, Communication power, Oxford: Oxford University Press, 2009, p. 69.

54. I. de Vries, Tantalisingly close: an archaeology of communication desires in discourses of mobile wireless media, Amsterdam University Press, Amsterdam 2012, p. I38.

55. Couldry, 'Liveness, "reality," and the mediated habitus'. Cf. De Vries, Tantalisingly close; Van Es, The paradox of liveness; J. Bolter \& R. Grusin, Remediation: understanding new media, The MIT-press, Cambridge I999.

56. Cf. the before mentioned intimacy of radio and television: Pease \& Dennis, Radio: the forgotten medium; Berenstein, 'Acting live'.

57. J. Vincent, 'Is the mobile phone a personalized social robot?', in: Intervalla, I, vol. I, 20I3, p. 60-70, retrieved from http://www.fc.edu/intervalla/index.php, p. 68.

58. Cf. De Vries, Tantalisingly close; Vincent, 'Is the mobile phone a personalized social robot?'.

59. Cf. Berry, The philosophy of software.

6o. Vincent, 'Is the mobile phone a personalized social robot?', p. 63.

6I. Cf. D. Okabe, 'Emergent social practices, situations and relations through everyday camera phone use', presentation at: 'International conference on mobile communication and social change', Seoul, Korea 2004, retrieved from: http://www.itofisher.com/mito/archives/okabe_seoul.pdf; J. van Dijck, 'Digital photography: communication, identity, memory', in: Visual communication, 7, vol. I, 2008, p. 57-76; N.A. van House, 'Personal photography, digital technologies and the uses of the visual', Visual Studies, 26, vol. 2, 20II, p. I25-I34; A.J. Aguayo \& S.J. Calvert, '(Re)capturing womanhood: perspectives and portraits through mobile photography', Visual communication quarterly, 20, vol. 3, 2013, p. 180-187.

62. Van House, 'Personal photography'; Van Dijck, 'Digital photography'.

63. Okabe, 'Emergent social practices'. 
100 | Tijdschrift voor Mediageschiedenis - I8 [I] 20 I5 